\title{
UnCertainty of Mechanical Calibration of GAUGE BLOCKS OF Dissimilar MATERIALS
}

\author{
GODINA, A.; TASIC, T. \& ACKO, B.
}

Abstract: For a national metrology laboratory and holder of national standard for length, capability of performing gauge block calibration by mechanical comparison with lowest possible uncertainty is of highest importance. Calibration of gauge blocks of dissimilar materials on the highest level is not wide spread, as bigger national laboratories tend to calibrate non-steel gauge blocks with reference gauge block of like material. For smaller laboratories this is economically not viable.

In present paper the uncertainty budget of mechanical calibration of gauge blocks of dissimilar materials, as a results of extensive analytical and experimental research, is presented in details.

Key words: gauge block, calibration, mechanical comparison, dissimilar materials
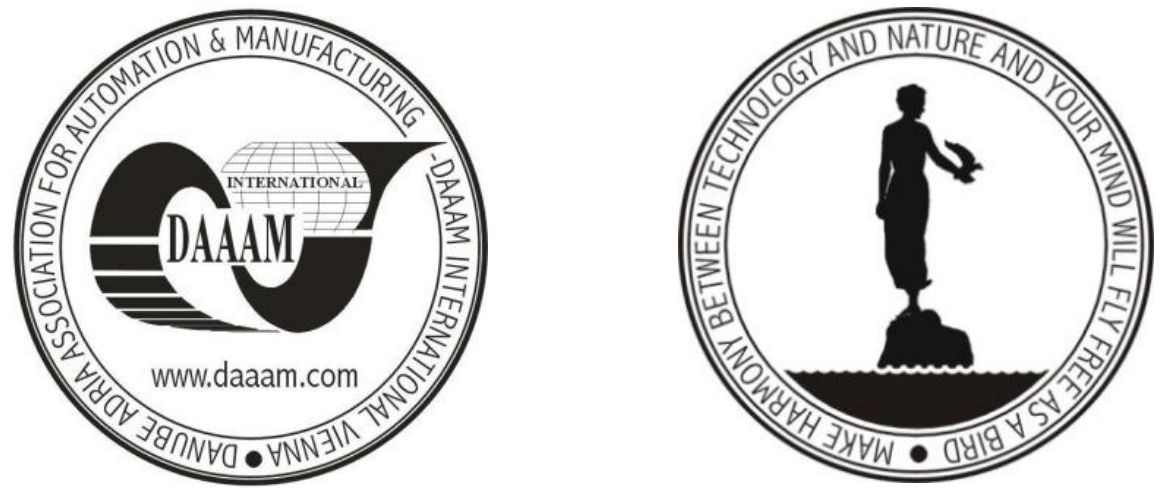

Authors' data: Dr. Sc. Godina, A[ndrej]; Tasic, T[adej]; Univ. Prof. Dr. Sc. Acko, B[ojan], University of Maribor, Faculty of mechanical engineering, Smetanova 17, 2000 Maribor, Slovenia, andrej.godina@uni-mb.si, tadej.tasic@uni-mb.si, bojan.acko@uni-mb.si

This Publication has to be referred as: Godina, A[ndrej]; Tasic, T[adej] \& Acko, B [ojan] (2010). Uncertainty of Mechanical Calibration of Gauge Blocks of Dissimilar Materials, Chapter 39 in DAAAM International Scientific Book 2010, pp. 431-444, B. Katalinic (Ed.), Published by DAAAM International, ISBN 978-3-901509-74-2, ISSN 1726-9687, Vienna, Austria

DOI: 10.2507/daaam.scibook.2010.39 


\section{Introduction}

Non-steel materials of gauge blocks are increasingly gaining its popularity, among them especially oxygen ceramics with its mechanical properties being close to the steel. Calibration of non-steel gauge blocks is therefore increasingly demanded. With the exemption of bigger national metrology laboratories, other calibrating laboratories only have steel reference gauge block set and therefore can not mechanical calibrate non-steel gauge blocs with the measurement uncertainty similar to those for steel.

For mechanical calibration of gauge blocks by comparison of dissimilar materials a significant increase in measurement uncertainty is typical. This is mainly the consequence of the differences in thermal expansion coefficients and uncertainty associated with the stylus penetration correction.

With precise temperature control effects of differences in thermal expansion coefficients can be minimised, while elastic deformation as a consequence of stylus force for mechanical comparison is unavoidable.

Uncertainty contributors for the case of calibration of gauge blocks of dissimilar materials by mechanical comparison are presented for both tungsten carbide and ceramics gauge blocks. The result of the research is comparatively small calibration uncertainties for mechanical calibration of non-steel gauge blocs by comparison with steel gauge blocs.

\section{Calibration laboratory as a maintainer of a national standard}

As a part of distributed system of national measurement standards, Laboratory for Production Measurement (LTM) at the Faculty for mechanical engineering, University of Maribor, is maintaining the national standard for length since 1998. Since the uncertainty of measurement in calibrations performed in LTM enters into the uncertainty budgets of calibration laboratories throughout the country, the uncertainty minimization is one of our highest ranked fields of research.

National standard for length in Slovenia comprise of 122-piece set of steel gauge blocks, ranging from $0,5 \mathrm{~mm}$ to $125 \mathrm{~mm}$ and some additional steel gauge blocks of length up to $1000 \mathrm{~mm}$. These gauge blocks will be referred to as reference gauge blocks.

Reference gauge blocks are calibrated externally in European highest rank metrological institution by primary standard. In the case of length that is interferometric method.

\section{Length standard: gauge block}

Gauge blocks are most accurate standards of length and an important basis of industrial length measurements, as well as the most important and commonly used measurement standards for maintaining traceability in dimensional metrology (Faust et al., 1998). They provide industry with reliable and traceable standards of length.

Gauge blocks are defined in standard ISO 3650 (1998), Geometrical product 
specifications (GPS) - Length standards - Gauge blocks (ISO 3650, 1998). Gauge block is length standard of rectangular shape, made of wearing resistant material. It comprises of pair of flat, mutually parallel measurement surfaces, which can be wrung to measurement surfaces of other gauge blocks and herewith joined (see Fig. 1). Gauge block can also be wrung onto wringing plate with similar surface quality, what is used at interferometric length measurement.

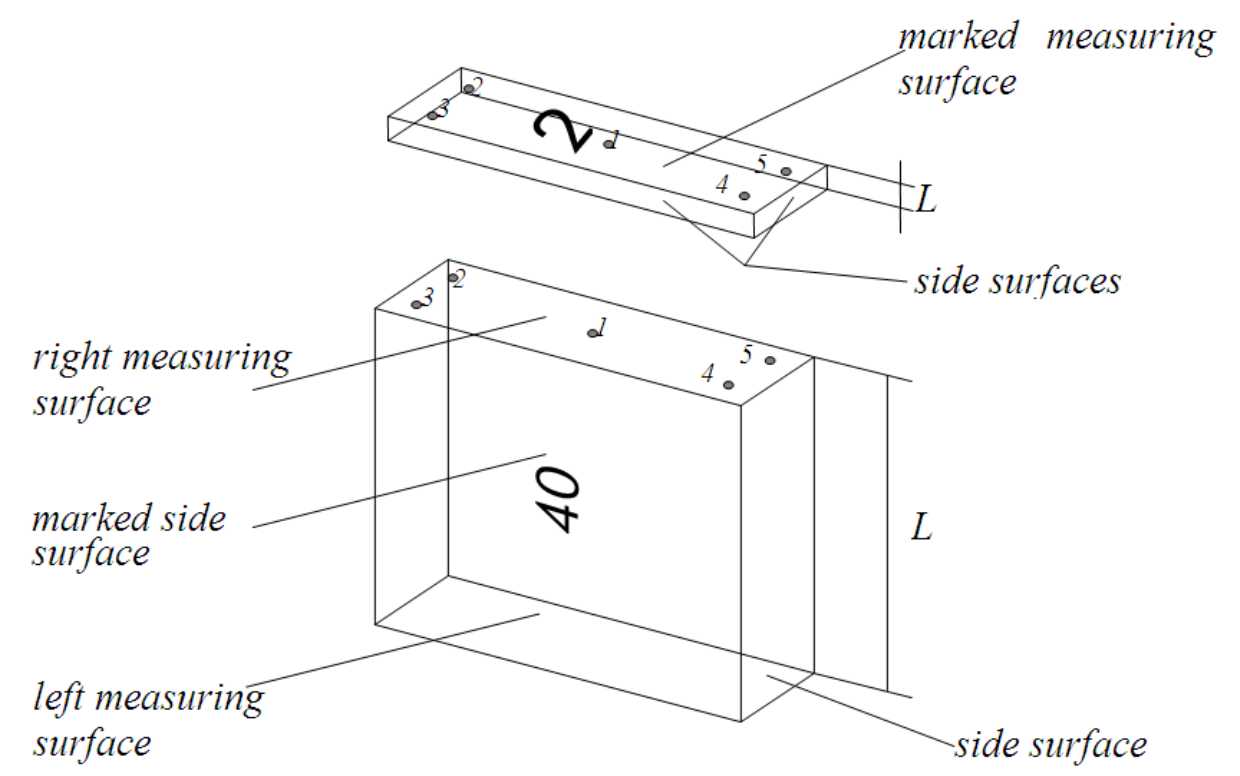

Fig. 1. Gauge blocks

Depending of gauge block length, two different dimensions of measuring surfaces exist:

\begin{tabular}{|c|c|}
\hline $\begin{array}{c}\text { Nominal dimension } L \\
\text { in } \mathrm{mm}\end{array}$ & $\begin{array}{c}\text { Dimension of measuring } \\
\text { surfaces in } \mathrm{mm}\end{array}$ \\
\hline $0,5 \leq L<10$ & $30 \times 9$ \\
\hline$L \geq 10$ & $35 \times 9$ \\
\hline
\end{tabular}

Tab. 1. Gauge block's dimensions of measuring surfaces

On a gauge block, nominal dimension, name or sign of the manufacturer and identification number are marked. Gauge blocks of dimension $L<6 \mathrm{~mm}$ are marked on the measuring surfaces, as shown in Fig. 1.

\section{Mechanical calibration of gauge blocks of dissimilar materials - why increased uncertainty?}

Gauge blocks are being calibrated by two methods: interferometric calibration and calibration by mechanical comparison to reference gauge block. While interferometric method represents primary level, comparison is more suitable for calibrating industrial gauge blocks because of lower costs and shorter calibration 
time. Although no significant changes in equipment happened in last decade, improvements in mechanical comparison are on-going (Godina et al., 2006). A short review of the Calibration and Measurement capabilities (CMC) (***BIPM 2009) shows that the ratio between high- and low-end uncertainties in mechanical calibration is approx. 1:3. That indicates the potential for further improvement in lowering the uncertainty.

Especially for national metrology laboratories, not performing interferometric gauge block calibration, capability of performing gauge block calibration by mechanical comparison with lowest possible uncertainty is of highest importance (Acko \& Sostar, 2002). Uncertainty of gauge block calibration at national metrology laboratory namely enters budgets of uncertainty evaluation of all industrial length calibration laboratories throughout the country.

When talking about mechanical comparison of gauge blocks, almost exclusively the comparison of gauge block of same materials is meant. Already cited CMC key comparison database reveals no reported comparison of gauge blocks by dissimilar materials. The reason for avoiding calibration of gauge blocks dissimilar materials lies in differences of their temperature extension and mechanical effects. Bigger calibration laboratories avoid the need for calibrating gauge blocks of dissimilar materials by acquiring additional reference set of tungsten carbide and/or ceramics, which is then interferometric calibrated (Decker et al., 2001). Unfortunately small laboratories have too small a customer base in these materials to justify the expense of additional reference sets (Mudronja et al., 2004).

For measurement uncertainty evaluation of mechanical calibration of gauge blocks of dissimilar materials two additional problems arise: uncertainty because of difference in thermal expansion coefficients and uncertainty associated with the stylus penetration correction (Acko, 2002). In following chapters, analytical and experimental approach in the research of the stylus penetration correction is presented.

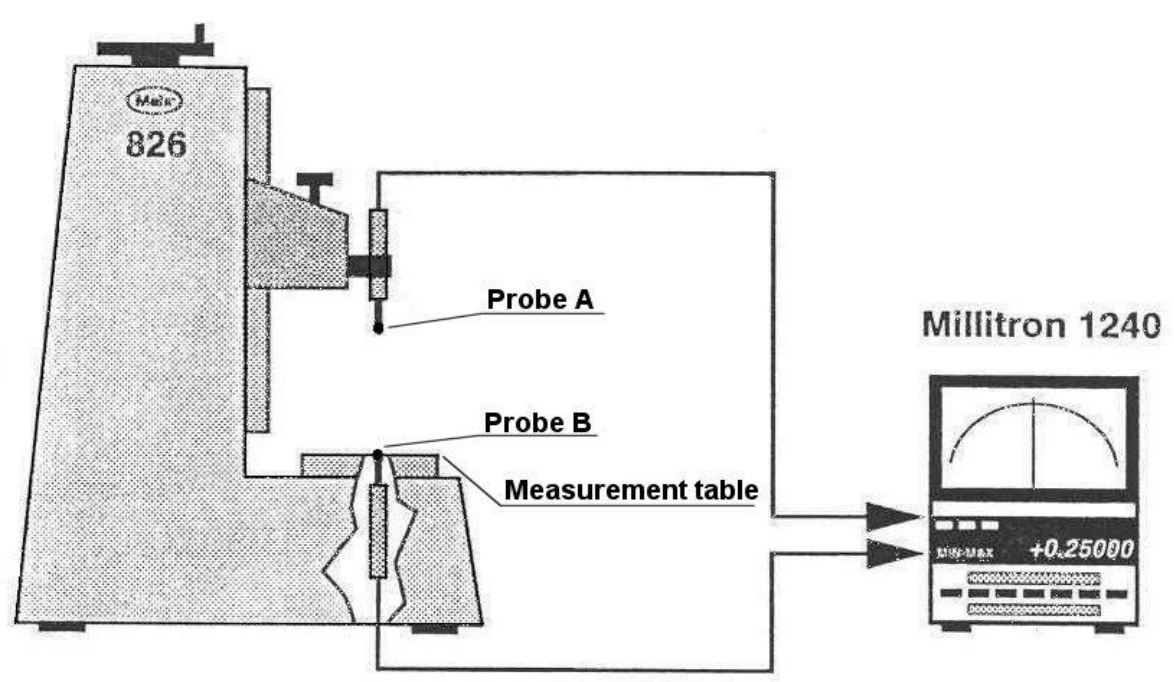

Fig. 2. Gauge block comparator (Mahr) 


\section{Gauge block comparator}

For calibration of gauge blocks of length up to $125 \mathrm{~mm}$ by mechanical comparison a contact comparator is used. Typical gauge block comparator (in our case Mahr 826) comprises of the measurement pedestal, the measurement table with the gauge block positioning device, two length indicators (probe A and B) connected to an electronic measuring instrument with numerical display (Mahr, 1995) (Fig. 2).

\section{Calibration of gauge blocks by mechanical comparison}

\subsection{Preparation for calibration}

Before calibration gauge blocks must be carefully cleaned and stored in the microclimatic chamber for at least 24 hours in order to get right temperature (Thalmann \& Baechler, 2003). Microclimatic conditions should be stabile temperature in the range of $20 \pm 0,3{ }^{\circ} \mathrm{C}$, actual temperature in the moment of probing enters into the measuring programme in order to calculate the temperature expansion correction.

\subsection{Performance of the measurement}

The measurement is supported by software, provided by comparator's manufacturer. In accordance with ISO 3650, for the highest level measurements five points are measured. The procedure is divided in the following steps:

- $\quad$ Measurement in the midpoint of the gauge block, resetting a display to $0,00 \mu \mathrm{m}$;

- Start of the measuring programme; entering the first measuring point;

- $\quad$ Entering measured temperature value;

Moving the gauge blocks to measure the midpoint of the gauge block $\mathrm{B}$ (measuring point No. 1 - see Fig. 1.)

- The point should be probed at least three times;

- Measurements in the points 2, 3, 4 and 5. Each point should be probed at least three times,

- $\quad$ Repeated measurement in the midpoint of the gauge block A: results of repeated measurements should lie in the tolerance of $0,02 \mu \mathrm{m}$ (otherwise the measurement is not valid and must be repeated).

\section{Additional corrections in the case of dissimilar materials}

\subsection{Correction of thermal expansion}

If gauge blocks 'A' and 'B' are made of equal materials, the expansions caused by temperature deviation $\delta \mathrm{t}$ (reference temperature is $20^{\circ} \mathrm{C}$ ) are equal. Therefore, a temperature expansion correction is not calculated.

After calibrations of temperature expansion coefficients of gauge blocks of tungsten carbide and ceramic from different producers, following values were adopted: when measuring ceramic gauge block, the temperature expansion coefficient 
of $\alpha=9,4 \cdot 10^{-6}{ }^{\circ} \mathrm{C}^{-1}$ shall be used, while for tungsten carbide gauge block $\alpha=4,4 \cdot 10^{-6}{ }^{\circ} \mathrm{C}^{-1}$ (for uncertainties of this values see chapter 0 ).

\subsection{Indentation correction}

\subsubsection{Experimental determination of difference in penetration}

Interferometric calibrated gauge blocks of $2 \mathrm{~mm}, 4 \mathrm{~mm}$ and $25 \mathrm{~mm}$ of steel, tungsten carbide and ceramics were used for experimental determination of indentation difference:

- Steel gauge blocks from primary set in LTM (Slovene national measurement standard for length),

- Tungsten carbide gauge blocks from different producers, purchased for this experiment (producers listed in Fig. 3 and Fig. 4),

- Ceramics gauge blocks from different producers.

- Steel gauge block was compared with tungsten carbide gauge block, as well as steel gauge block with ceramic. Each pair was measured eight times. Results show very good repeatability, as shown on Fig. 3 and Fig. 4.

Scattering of results was small, mainly a result of resolution of the comparator, which was $10 \mathrm{~nm}$. Mean values of penetration difference of particular pair in comparison are:

- between $56 \mathrm{~nm}$ and $65 \mathrm{~nm}$ for the pair steel gauge block - tungsten carbide gauge block,

- between $0 \mathrm{~nm}$ and $6 \mathrm{~nm}$ for the pair steel gauge block - ceramics gauge block.

Means span in size of $9 \mathrm{~nm}$ resp. $6 \mathrm{~nm}$ is a consequence of comparator resolution and could be avoided only with changes in comparator.

\subsection{Comparison of analytical and experimental results}

The following results of stylus penetration differences at mechanical comparison of gauge blocks of dissimilar materials are presented in Tab. 2:

- Values, calculated by use of Hertzian formulas (Puttock \& Thwaite, 1969);

- Experimentally established values,

- Pre-set values in gauge block comparator software by its manufacturer Mahr;

- Values, adopted in LTM.

Substantial differences between analytical and experimental values at combination steel gauge block - TC gauge block are obvious. 


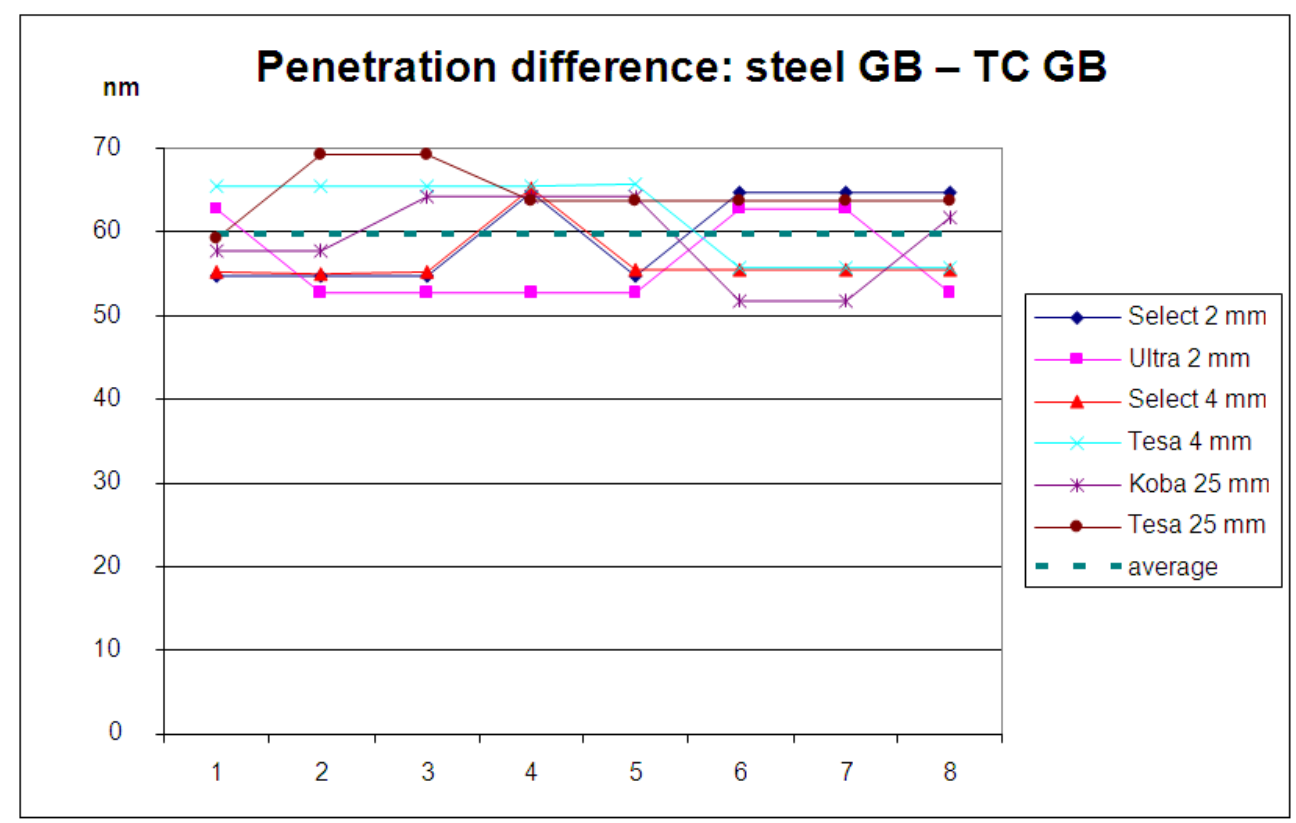

Fig. 3. Results of experimental determination of difference in stylus penetration steel and TC gauge block

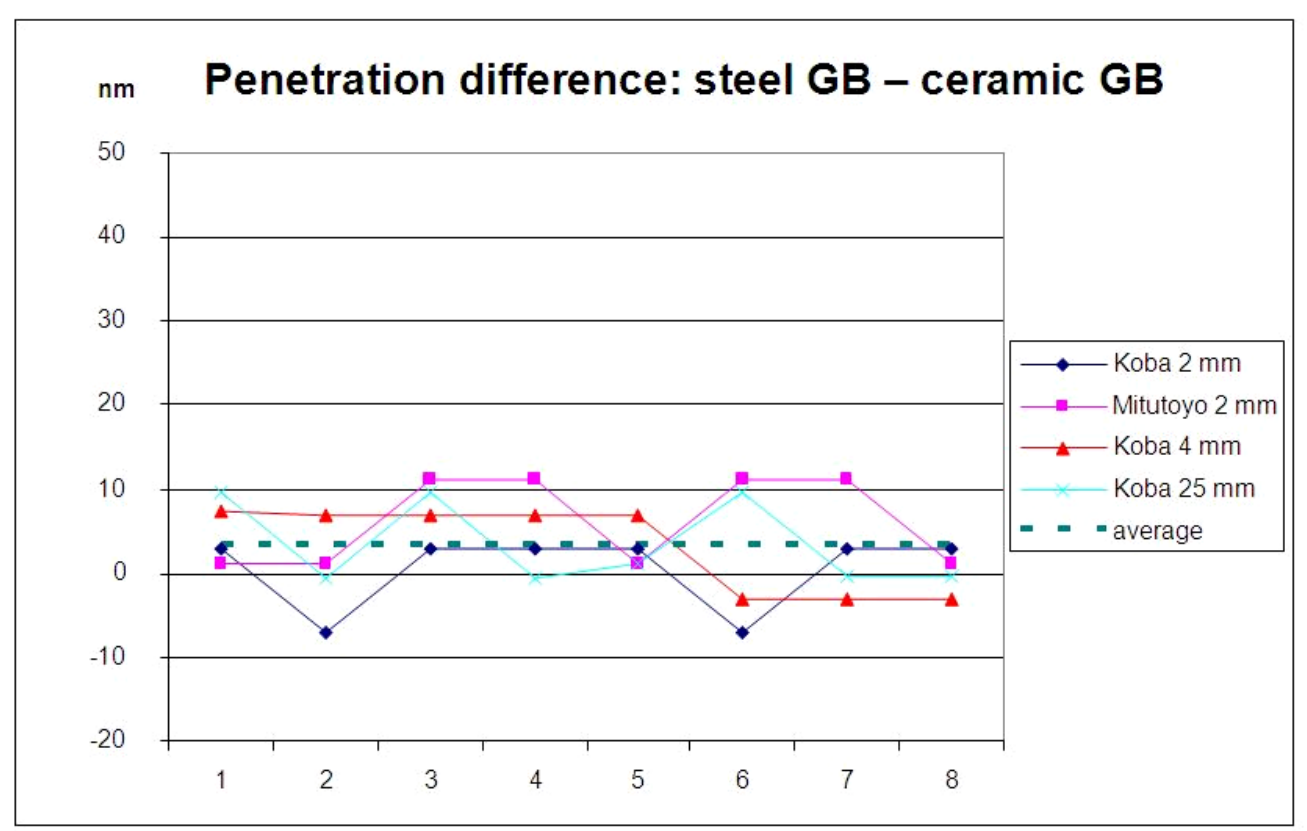

Fig. 4. Results of experimental determination of difference in stylus penetration steel and ceramic gauge block

Mean value of experimentally established stylus penetration difference between steel and TC Gauge blocks is $60 \mathrm{~nm}$, while analytical result is twice as much. The difference deserves attentive analysis. Canadian national laboratory also states in (Decker et al., 1998) that they measured $40 \mathrm{~nm}$ when analytical result was $90 \mathrm{~nm}$, thus $50 \mathrm{~nm}$ difference. Similarly, the comparator manufacturer states correction of 50 nm (Tab. 2).

In LTM we decided to adopt experimentally established values for stylus penetration correction. 
In the case of comparison of steel gauge block with ceramic gauge block stylus penetration correction is not needed. Analytical value of $4 \mathrm{~nm}$ is negligible small, as are results of experiments in amount of $-3 \mathrm{~nm}$. Experimental results of some other laboratories (Doiron, Beers, 2005) also show that correction is not required.

\begin{tabular}{|c|c|c|c|c|}
\hline $\begin{array}{c}\text { material of } \\
\text { custom gauge } \\
\text { block }\end{array}$ & analytical result & $\begin{array}{c}\text { experimental } \\
\text { result }\end{array}$ & $\begin{array}{c}\text { pre-set } \\
\text { correction by } \\
\text { comparator } \\
\text { manufacturer }\end{array}$ & $\begin{array}{c}\text { correction, used } \\
\text { in LTM }\end{array}$ \\
\hline ceramics & 4 & -3 & 0 & 0 \\
\hline TC & -126 & -60 & -50 & -60 \\
\hline
\end{tabular}

Tab. 2. Correction values for stylus penetration (in $\mathrm{nm}$ )

\section{Calibration uncertainty analysis for the case of gauge blocks of different materials}

Calibration uncertainty analysis follows ISO Guide to the expression of uncertainty in measurement (ISO Guide 1995), as well as European Accreditation publication Expressions of the Uncertainty of Measurements in Calibration (EA-4/02, 1999).

\subsection{Mathematical model of the measurement}

The length $L_{x}$ of the gauge block being calibrated is given by the expression:

$$
L_{x}=L_{s}+\delta L_{d}+\delta L+\delta L_{c}+L\left(\alpha_{s} t_{s}-\alpha_{x} \delta t-\alpha_{x} t_{s}\right)-\Delta-\delta L_{V}
$$

where:

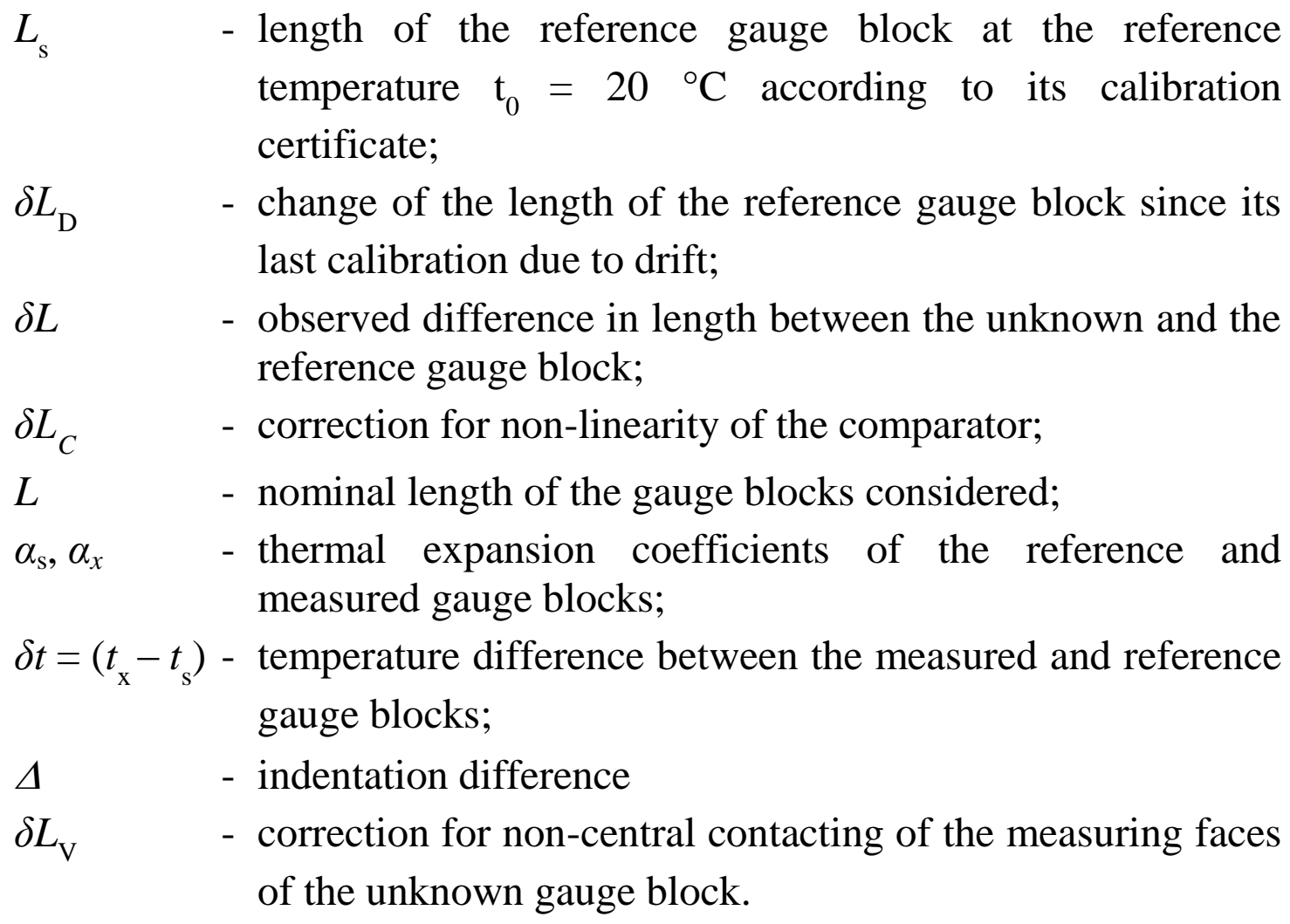


8.2 Standard uncertainties of the estimations of the input values and combined standard uncertainty of measurement

Combined standard uncertainty is expressed by the uncertainties of the input values by the following equation:

$$
\begin{gathered}
u_{\mathrm{s}}{ }^{2}\left(L_{\mathrm{x}}\right)=\mathrm{c}_{L \mathrm{~s}}{ }^{2} \mathrm{u}^{2}\left(L_{\mathrm{s}}\right)+\mathrm{c}_{\delta L_{\mathrm{D}}}{ }^{2} \mathrm{u}^{2}\left(\delta L_{\mathrm{D}}\right)+\mathrm{c}_{\delta L}{ }^{2} \mathrm{u}^{2}(\delta L)+\mathrm{c}_{\delta L_{\mathrm{C}}}{ }^{2} \mathrm{u}^{2}\left(\delta L_{\mathrm{C}}\right)+\mathrm{c}_{\alpha_{s}}{ }^{2} \mathrm{u}^{2}\left(\alpha_{s}\right)++\mathrm{c}_{t_{s}}{ }^{2} \mathrm{u}^{2}( \\
\left.t_{s}\right)+\mathrm{c}_{\alpha_{x}}{ }^{2} \mathrm{u}^{2}\left(\alpha_{x}\right)+\mathrm{c}_{\delta \mathrm{t}}{ }^{2} \mathrm{u}^{2}(\delta t)+\mathrm{c}_{\Delta}{ }^{2} \mathrm{u}^{2}(\Delta)+\mathrm{c}_{\delta L_{\mathrm{V}}}{ }^{2} \mathrm{u}^{2}\left(\delta L_{\mathrm{V}}\right) \\
\text { where } \mathrm{c}_{\mathrm{i}} \text { are partial derivatives of the function }(): \\
\mathrm{c}_{L \mathrm{~s}}=\partial \mathrm{f} / \partial L_{\mathrm{s}}=1 \\
\mathrm{c}_{\delta L_{\mathrm{D}}}=\partial \mathrm{f} / \partial \delta L_{\mathrm{D}}=1 \\
\mathrm{c}_{\delta L}=\partial \mathrm{f} / \partial \delta L=1 \\
\mathrm{c}_{\delta L_{\mathrm{C}}}=\partial \mathrm{f} / \partial \delta L_{\mathrm{C}}=1 \\
\mathrm{c}_{\alpha_{s}}=\partial \mathrm{f} / \partial \alpha_{s}=L t_{s} \\
\mathrm{c}_{t_{s}}=\partial \mathrm{f} / \partial t_{s}=L\left(\alpha_{s}-\alpha_{x}\right) \\
\mathrm{c}_{\alpha_{x}}=\partial \mathrm{f} / \partial \alpha_{x}=-L \delta t \\
\mathrm{c}_{\delta \mathrm{t}}=\partial \mathrm{f} / \partial \delta t=-L \alpha_{x} \\
\mathrm{c}_{\Delta}=\partial \mathrm{f} / \partial \Delta=-1 \\
\mathrm{c}_{\delta \mathrm{L}_{\mathrm{V}}}=\partial \mathrm{f} / \partial \delta L_{\mathrm{v}}=-1
\end{gathered}
$$

Standard uncertainties of the input values are evaluated (estimated) for the applied equipment and method as well as for supposed measurement conditions.

8.2.1 Uncertainty of the reference standard length $u\left(L_{S}\right)$ :

The uncertainty of the reference gauge block calibration is given in the calibration certificate of the set of gauge blocks as

$$
U=\sqrt{(20 n m)^{2}+\left(0,18 \cdot 10^{-6} \cdot L\right)^{2}}
$$

(coverage factor $k=2$ ).

Standard uncertainty is therefore:

$$
u=\sqrt{(10 \mathrm{~nm})^{2}+\left(0,09 \cdot 10^{-6} \cdot L\right)^{2}}
$$

\subsubsection{Uncertainty caused by the drift of the standard $u\left(\delta L_{D}\right)$}

The temporal drift of the length of the reference gauge block is estimated from previous calibrations to be zero with limits $\pm 0,2 \cdot 10^{-6}$. L.

General experience with gauge blocks of this type suggests that zero drift is most probable and that a triangular probability distribution can be assumed.

Standard uncertainty is therefore:

$$
u=0,2 \cdot 10^{-6} \cdot L / \sqrt{6}=0,082 \cdot 10^{-6} \cdot L
$$


8.2.3 Uncertainty of the observed difference in length between the unknown and the reference gauge block $(\delta L)$

The measured difference can be expressed by the equation:

$$
\delta L=r-e_{\mathrm{s}}
$$

where:

$$
\begin{array}{lll}
\delta L & - & \text { observed difference in length } \\
r & - & \text { reading } \\
e_{\mathrm{s}} & - & \text { offset of the comparator, observed during calibration }
\end{array}
$$

The uncertainty of the observed difference in length is therefore:

$$
u(\delta L)=\sqrt{u(r)^{2}+u\left(e_{s}\right)^{2}}
$$

The uncertainty of the reading can be expressed from the known interval in which the result is rounded. The comparator resolution is $10 \mathrm{~nm}$, therefore the interval of rounding is $\pm 5 \mathrm{~nm}$. Since the distribution is rectangular, the standard uncertainty is:

$$
u(r)=5 / \sqrt{3}=2,89 \mathrm{~nm}
$$

The uncertainty of the offset evaluation is stated in the calibration report. The comparator has been calibrated in LTM. The uncertainty in the calibration certificate is:

$$
U=20 \mathrm{~nm}+0,2 \cdot 10^{-6} \cdot L ; k=2
$$

Standard uncertainty is therefore:

$$
u=10 \mathrm{~nm}+0,1 \cdot 10^{-6} \cdot L
$$

This formula can be expressed in a quadratic form considering uncertainties on the lower and the upper measurement range limits $(0,5 \mathrm{~mm}$ and $100 \mathrm{~mm})$ :

$$
u(\mathrm{cal})=\sqrt{(10 \mathrm{~nm})^{2}+\left(0,17 \cdot 10^{-6} \cdot \mathrm{L}\right)^{2}}
$$

Total uncertainty of the observed difference in length is:

$$
u(\delta L)=\sqrt{(10,5 \mathrm{~nm})^{2}+\left(0,17 \cdot 10^{-6} \cdot L\right)^{2}}
$$

The offset itself is not corrected during the calibration of gauge blocks, but is not allowed to exceed the resolution during the calibration of the comparator (in such case the probes should be tested and replaced if necessary).

\subsubsection{Uncertainty of the correction for non-linearity of the comparator $\left(\delta L_{C}\right)$}

Taking into account the tolerances of the grade 0 gauge block to be calibrated and the grade $\mathrm{K}$ reference gauge block, the maximum length difference will be within $\pm 1,8 \mu \mathrm{m}$ leading to unidentifiable limits for non-linearity of the comparator used (Godina \& Acko, 2004).

\subsubsection{Uncertainty of temperature expansion coefficient $u\left(\alpha_{s}\right)$}

Experience values $\pm 0,5 \cdot 10^{-6 \circ} \mathrm{C}^{-1}$ and rectangular distribution (equal possibility over entire interval) are assumed. Standard uncertainty is therefore:

$$
u\left(\alpha_{e}\right)=\left(0,5 \cdot 10^{-6}{ }^{\circ} C^{-1}\right) / \sqrt{3}=0,289 \cdot 10^{-6}{ }^{\circ} C^{-1}
$$


8.2.6 Uncertainty of temperature difference between the unknown and reference gauge blocks $u(\delta t)$

Concerning the temperature measurements in the entire measuring space it can be assumed that the difference in temperatures of the gauges lies with an equal probability in an interval $\pm 0,02{ }^{\circ} \mathrm{C}$.

The standard uncertainty is therefore:

$$
u(\delta t)=\left(0,02{ }^{\circ} \mathrm{C}\right) / \sqrt{3}=0,0115^{\circ} \mathrm{C}
$$

8.2.7 Uncertainty of temperature expansion coefficient of measured gauge block $u\left(\alpha_{x}\right)$

Interval of the temperature expansion coefficients of ceramic and TC gauge block was experimentally evaluated. It was found out to be $\pm 1 \cdot 10^{-6}{ }^{\circ} \mathrm{C}^{-1}$. Standard uncertainty at supposed rectangular distribution is:

$$
u\left(\alpha_{x}\right)=\left(1,0 \cdot 10^{-6}{ }^{\circ} C^{-1}\right) / \sqrt{3}=0,58 \cdot 10^{-6}{ }^{\circ} C^{-1}
$$

8.2.8 Uncertainty of the reference gauge block temperature $u\left(t_{s}\right)$

\section{- Uncertainty of the temperature measurement system}

The calibration certificate gives an uncertainty of $U=5 \mathrm{mK}$ with $k=2$. Standard uncertainty is therefore:

$$
u\left(\theta_{1}\right)=5 \cdot 10^{-3} / 2=0,0025^{\circ} \mathrm{C}
$$

- Uncertainty because of the difference between the table temperature and the mean temperature of the standard

The difference between the table temperature and the mean temperature of the standard was calculated from 80 measurements to be $0,025{ }^{\circ} \mathrm{C}$ with the standard deviation of $0.022{ }^{\circ} \mathrm{C}$. This difference is assumed to be a random error and contributes to the uncertainty. The total uncertainty is:

$$
u(\Delta \theta)=\sqrt{0,025^{2}+0,022^{2}}=0,033^{\circ} \mathrm{C}
$$

- Uncertainty caused by temperature variation

The temperature is recorded every two hours. Therefore, variations in an interval of two hours were calculated from 24 measurements and were found to be $0,06{ }^{\circ} \mathrm{C}$. Since these variations were cyclic, U-shaped distribution was used to calculate the standard uncertainty:

$$
u\left(\theta_{2}\right)=0,06 / \sqrt{2}=0,042^{\circ} \mathrm{C}
$$

- The total uncertainty of the reference gauge block temperature $u(t s)$

$$
u(\Delta \bar{t})=\sqrt{u\left(\theta_{1}\right)^{2}+u(\Delta \theta)^{2}+u\left(\theta_{2}\right)^{2}}=0,053^{\circ} \mathrm{C}
$$


Godina, A.; Tasic, T. \& Acko, B.: Uncertainty of Mechanical Calibration of ...

\begin{tabular}{|c|c|c|c|c|c|}
\hline \begin{tabular}{|c|} 
Quan \\
tity
\end{tabular} & $\begin{array}{c}\text { Evaluated } \\
\text { value }\end{array}$ & Standard uncertainty & $\begin{array}{l}\text { Distri- } \\
\text { bution }\end{array}$ & $\begin{array}{l}\text { Sensitivity } \\
\text { coefficient }\end{array}$ & Uncertainty contribution \\
\hline$\overline{L_{\mathrm{s}}}$ & $100 \mathrm{~mm}$ & $\sqrt{(10 \mathrm{~nm})^{2}+\left(0,09 \cdot 10^{-6} \cdot L\right)^{2}}$ & normal & 1 & $\sqrt{(10 \mathrm{~nm})^{2}+\left(0,09 \cdot 10^{-6} \cdot L\right)^{2}}$ \\
\hline$\delta L_{\mathrm{D}}$ & $0 \mathrm{~mm}$ & $0,082 \cdot 10^{-6} \cdot \mathrm{L}$ & $\begin{array}{l}\text { train- } \\
\text { gular }\end{array}$ & 1 & $0,082 \cdot 10^{-6} \cdot \mathrm{L}$ \\
\hline$\delta L$ & $0 \mathrm{~nm}$ & $\sqrt{(10,5 n m)^{2}+\left(0,17 \cdot 10^{-6} \cdot L\right)^{2}}$ & normal & 1 & $\sqrt{(10,5 n m)^{2}+\left(0,17 \cdot 10^{-6} \cdot L\right)^{2}}$ \\
\hline$\delta L_{\mathrm{C}}$ & $0 \mathrm{~mm}$ & negligible & normal & 1 & negligible \\
\hline$\alpha_{\mathrm{s}}$ & $11,5 \cdot 10^{-6 \circ} \mathrm{C}^{-1}$ & $0,289 \cdot 10^{-6}{ }^{\circ} \mathrm{C}^{-1}$ & $\begin{array}{l}\text { rectan- } \\
\text { gular }\end{array}$ & $0,1^{\circ} \mathrm{C} \cdot \mathrm{L}$ & $-0,030 \cdot 10^{-6} \cdot \mathrm{L}$ \\
\hline$\delta \mathrm{t}$ & $0^{\circ} \mathrm{C}$ & $0,0115^{\circ} \mathrm{C}$ & normal & $-9,4 \cdot 10^{-6}{ }^{\circ} \mathrm{C}^{-1} \cdot \mathrm{L}$ & $-0,108 \cdot 10^{-6} \cdot \mathrm{L}$ \\
\hline \multirow{2}{*}{$\alpha_{x}$} & $\begin{array}{c}\text { TC: } \\
4,4 \cdot 10^{60} \mathrm{C}^{-1}\end{array}$ & $0,58 \cdot 10^{-6}{ }^{\circ} \mathrm{C}^{-1}$ & $\begin{array}{l}\text { rectan- } \\
\text { gular }\end{array}$ & $-0,05^{\circ} \mathrm{C} \cdot \mathrm{L}$ & $-0,029 \cdot 10^{-6} \cdot \mathrm{L}$ \\
\hline & $\begin{array}{c}\text { ceramics: } \\
9,4 \cdot 10^{60} \mathrm{C}^{1}\end{array}$ & $0,58 \cdot 10^{-6}{ }^{\circ} \mathrm{C}^{-1}$ & $\begin{array}{l}\text { rectan- } \\
\text { gular }\end{array}$ & $-0,05^{\circ} \mathrm{C} \cdot \mathrm{L}$ & $-0,029 \cdot 10^{-6} \cdot \mathrm{L}$ \\
\hline \multirow{2}{*}{$t_{s}$} & $\begin{array}{l}\text { TC: } \\
0^{\circ} \mathrm{C}\end{array}$ & $0,053^{\circ} \mathrm{C}$ & normal & $-7,1 \cdot 10^{-6} \mathrm{C}^{-1} \cdot \mathrm{L}$ & $-0,376 \cdot 10^{-6} \cdot \mathrm{L}$ \\
\hline & $\begin{array}{l}\text { ceramics: } \\
0^{\circ} \mathrm{C}\end{array}$ & $0,053^{\circ} \mathrm{C}$ & normal & $-2,1 \cdot 10^{-6}{ }^{\circ} \mathrm{C}^{-1} \cdot \mathrm{L}$ & $-0,111 \cdot 10^{-6} \cdot \mathrm{L}$ \\
\hline \multirow{2}{*}{$\Delta$} & $\begin{array}{l}\text { TC: } \\
60 \mathrm{~nm}\end{array}$ & $20 \mathrm{~nm}$ & normal & -1 & $20 \mathrm{~nm}$ \\
\hline & $\begin{array}{c}\text { ceramics: } \\
0 \mathrm{~nm}\end{array}$ & $20 \mathrm{~nm}$ & normal & -1 & $20 \mathrm{~nm}$ \\
\hline \multirow[t]{3}{*}{$\delta l_{v}$} & $0 \mathrm{~nm}$ & $4 \mathrm{~nm}$ & normal & 1 & $4 \mathrm{~nm}$ \\
\hline & & & & Total TC: & $\sqrt{(25,0 \mathrm{~nm})^{2}+\left(0,45 \cdot 10^{-6} \cdot L\right)^{2}}$ \\
\hline & & & & Total ceramics: & $\sqrt{(25,0 \mathrm{~nm})^{2}+\left(0,26 \cdot 10^{-6} \cdot L\right)^{2}}$ \\
\hline
\end{tabular}

Tab. 3. Standard uncertainties of the input value estimations and total standard uncertainty

\subsubsection{Uncertainty of the indentation difference $u(\Delta)$}

Standard deviation of calculated corrections for all lengths and producers was taken as standard uncertainty:

$$
u_{p r}(\Delta)=9 \mathrm{~nm}
$$

Due to relatively small sample size the uncertainty was raised to:

$$
u(\Delta)=20 \mathrm{~nm}
$$

\subsubsection{Uncertainty of the correction for non-central contacting of the measuring} faces of the unknown gauge block $u\left(\delta L_{V}\right)$

For gauge blocks of grade 0 the variation in length determined from measurements at the centre and the four corners has to be within $\pm 0,12 \mu \mathrm{m}$ (ISO 
$3650,1998)$. Assuming that this variation occurs on the measuring faces along the short edge of length $9 \mathrm{~mm}$ and that the central length is measured inside a circle of radius $0,5 \mathrm{~mm}$, the deviation due to central misalignment of the contacting point is estimated to be within an interval of $\pm 7 \mathrm{~nm}$. Standard uncertainty at supposed rectangular distribution is therefore:

$$
u\left(\delta L_{v}\right)=(7 \mathrm{~nm}) / \sqrt{3}=4,0 \mathrm{~nm}
$$

\subsection{Expanded uncertainty of measurement}

Rounded expanded uncertainty for TC gauge blocks, when using the primary gauge block, is:

$$
U=\sqrt{(50 \mathrm{~nm})^{2}+\left(0,9 \cdot 10^{-6} \cdot L\right)^{2}} ; k=2
$$

Rounded expanded uncertainty ceramics gauge blocks, when using the primary gauge block set, is:

$$
U=\sqrt{(50 \mathrm{~nm})^{2}+\left(0,55 \cdot 10^{-6} \cdot L\right)^{2}} ; k=2
$$

\section{Conclusion}

Gauge block calibration by mechanical comparison, as a secondary option for highest-level gauge blocks calibration, is inferior to interferometric only in increased uncertainty of the results.

However, its instrumentation is less expensive and its procedure much simpler and faster, that is why it is widely used in calibration laboratories throughout the engineering industry.

As a national metrology laboratory for length, not performing interferometric gauge block calibration, we were handicapped by non-capability of accredited calibrating gauge blocks of dissimilar materials.

After extensive experimental research considering stylus penetration, as well as thorough analytical approach, we succeeded in minimising calibration uncertainty for the case of comparison of dissimilar materials. Procedure was already successfully accredited. Our next step will be entering an additional Calibration and measurement capability (CMC) into key comparison database at BIPM.

\section{References}

Acko, B. (2002). The experimental validation of an analytical calculation of sphere's deformation that results from probing force during calibration. Strojniski vestnik 48, 1, 2-8

Acko, B., Sostar A. (2002). Modification of the model for measurement evaluation in a gauge block calibration based on measurement automation. Strojniski vestnik $48,1,9-16$ 
Decker, J. et al. (2001). Two-part study toward lowest uncertainty calibration of ceramic gauge blocks: interferometry and mechanical comparison techniques. Proceedings of SPIE Vol. 4401

Decker, J. et al. (1998). Uncertainty of Gauge Block Calibration by Mechanical Comparison: A Worked Example for Gauge Blocks of Dissimilar Materials, In: Proceedings of SPIE Vol. 3477

Doiron, T., Beers J. (2005). The Gauge Block Handbook. NIST Monograph 180. Available from: http://emtoolbox.nist.gov/Publications/NISTMonograph180.asp. Accessed on: 2009-07-01

EA-4/02 (1999). Expressions of the Uncertainty of Measurements in Calibration. European Accreditation, 1999

Faust, B. et al. (1998). Minimizing Error Sources in Gage Block Mechanical Comparison Measurements. Proceedings of SPIE Vol. 3477

Godina, A., Acko B. (2004). Influence of the Measurement Force on the Uncertainty of the Gauge Block Comparator. In: VDI-Berichte 1860, Duesseldorf, pp. 763769

Godina, A., Acko, B. \& Drnovsek, J. (2006). Stylus penetration correction for the calibration of gauge blocks of dissimilar materials by mechanical comparison. Strojarstvo, 48, 3/4, 149-156

ISO 3650 (1998). Geometrical product specifications (GPS) - Length standards Gauge blocks. International Organization for Standardization

ISO Guide (1995). ISO Guide to the expression of uncertainty in measurement. International Organization for Standardization

Puttock, M., Thwaite, E. (1969). Elastic Compression of Spheres and Cylinders at Point and Line Contact. CSIRO

Thalmann, R., Bächler H. (2003). Isues and advantages of gauge block calibration by mechanical comparison. In: Proceedings of SPIE Vol. 5190, Decker J.E., Brown N. (Ed.), pp. 62-69

Mahr (1995). Betriebsanleitung : Endmaßgerät 826. Mahr GmbH, Göttingen

Mudronja, V., Mahovic, S. \& Runje, B. (2004). Determining the difference between estimated and realised measurement uncertainty based on comparative measurements. Strojarstvo, Vol. 46, No. 4-6, pp. 115-124

*** http://kcdb.bipm.org/AppendixC/ - BIPM Key Comparison Database, Appendix C: Calibration and Measurement Capabilities of National Metrology Institutes, Length. Accesed on: 2009-07-01 